\title{
Influences of Elevated Thermal Decomposition of Ammonia Gas on Indium Nitride Grown by Sol-Gel Spin Coating Method
}

\author{
$\underline{\text { Zhi Yin (Lee) })^{1,2}}$, Sha Shiong $(\mathrm{Ng})^{1}$, Fong Kwong $(\text { Yam })^{2}$ \\ ${ }^{1}$ Institute of Nano-Optoelectronics Research and Technology (INOR), Universiti Sains \\ Malaysia, 11800, Minden, Penang, Malaysia. \\ ${ }^{2}$ School of Physics, Universiti Sains Malaysia, 11800, Minden, Penang, Malaysia.
}

$$
\text { lee_zhiyin2003@yahoo.com }
$$

Indium nitride ( $\mathrm{InN}$ ) with unique properties such as small energy band gap of $0.7 \mathrm{eV}$, high electron affinity and carrier density, is a potential semiconductor material in the applications of optical and electronic devices $[1,2]$. Despite, the suitable growth conditions of InN are very stringent due to its low dissociation temperature and volatility of atomic nitrogen [3]. In this study, InN thin films grown on aluminium nitride (AIN) on p-type silicon(111) [AIN/p-type $\mathrm{Si}(111)]$ substrates are prepared via sol-gel spin coating method followed by nitridation process. Sol-gel spin coating is a low cost, fast processing and dilute solution based deposition method to produce thin and uniform film on substrate. The spin-coater is programmed to operate in a two-step spin profile; the first spinning speed is slower than the second. In subsequent, two three-zone tube furnaces connected in parallel manner are used for nitriding process; the passage of ammonia gas (NH3) into the first furnace is decomposed to produce reactive nitrogen radicals and brought into the second furnace for crystallization of $\operatorname{InN}$ at 600 ${ }^{\circ} \mathrm{C}$. The effects of thermal decomposition of $\mathrm{NH} 3$ gas on structural properties and surface morphologies of the deposited films are explored. X-ray diffraction results reveal that the crystalline quality of InN degrades markedly with increasing thermal decomposition of NH3 gas from 700 to $850^{\circ} \mathrm{C}$; in which, the association of indium oxide in the deposited film is detected. In the meantime, thermal etching effect and formation of indium droplet on the film can be observed at $850^{\circ} \mathrm{C}$; the findings are aligned with the cross-sectional analysis obtained by energy dispersive spectroscopy attached field-emission scanning electron microscopy, where the film thickness is found to be reduced tremendously. This phenomenon is mainly due to the increase of hydrogen partial pressure at elevated thermal decomposition of NH3 gas. On the other hand, the film surface with densely packed $\mathrm{InN}$ grains and film thickness of approximately to $620 \mathrm{~nm}$ is obtained at $700{ }^{\circ} \mathrm{C}$. The results deduce that this temperature is in favor for the growth of InN thin films.

\section{Keywords: Indium nitride, sol-gel spin coating, characterizations, thermal decomposition}

[1] WALTHER, R., LITVINOR, D. FOTOUHI, M., SCHNEIDER, R., GERTHSEN, D., VOHRINGER, R., HU, D. Z. \& SCHAADT, D. M. 2012. Microstructure of PAMBE grown InN layers on Si(111). Journal of Crystal Growth, 340, 34-40.

[2] XIE, Z. Y., ZHANG, R., XIU, X. -Q., LIU, B., LI, L., HAN, P., GU, S. -L., SHI, Y. \& ZHENG, Y. -D.. 2007. Growth and Characterization of InN Thin Films on Sapphire by MOCVD. Chinese Physics Letters, 24, 1004-1006.

[3] MCCHESNEY, J. B. BRIDENBAUGH, P. M. \& O'CONNOR, P. B. 1970. Thermal Stability of Indium Nitride at Elevated Temperatures and Nitrogen Pressure. Materials Research Bulletin, 5, 783-792. 